\title{
Analysis of lifestyle factors in patients with concomitant chronic pancreatitis and liver cirrhosis
}

\section{Aghdassi, Ali A.}

2017

Aghdassi , A A , Schneider , A , Kahl , M , Schuette , K, Kuliaviene , I, Salacone , P , Lutz , J , Tukiainen, E , Simon, P , Schauer , B , Uomo, G , Hauge , T \& Ceyhan, G O 2017 , ' Analysis of lifestyle factors in patients with concomitant chronic pancreatitis and liver cirrhosis ' , Pancreatology , vol. 17 , no. 5 , pp. 698-705 . https://doi.org/10.1016/j.pan.2017.07.194

http://hdl.handle.net/10138/298081

https://doi.org/10.1016/j.pan.2017.07.194

publishedVersion

Downloaded from Helda, University of Helsinki institutional repository.

This is an electronic reprint of the original article.

This reprint may differ from the original in pagination and typographic detail.

Please cite the original version. 


\title{
Analysis of lifestyle factors in patients with concomitant chronic pancreatitis and liver cirrhosis
}

\author{
Ali A. Aghdassi ${ }^{\text {a, }}$, Alexander Schneider ${ }^{\text {b }}$, Matthias Kahl ${ }^{c}$, Kerstin Schütte ${ }^{\mathrm{d}}$, \\ Irma Kuliaviene ${ }^{\mathrm{e}}$, Paola Salacone ${ }^{\mathrm{f}}$, Jon Lutz ${ }^{\mathrm{g}}$, Eija Tukiainen ${ }^{\mathrm{h}}$, Peter Simon ${ }^{\mathrm{a}}$, \\ Birgit Schauer ${ }^{\mathrm{i}}$, Generoso Uomo ${ }^{\mathrm{j}}$, Truls Hauge ${ }^{\mathrm{k}}$, Güralp O. Ceyhan ${ }^{1}$ \\ a Department of Medicine A, University Medicine Greifswald, Greifswald, Germany \\ ${ }^{\mathrm{b}}$ Department of Medicine II, University Medical Center Mannheim, University of Heidelberg, Mannheim, Germany \\ ${ }^{\mathrm{c}}$ Israelitisches Krankenhaus Hamburg, Hamburg, Germany \\ d Department of Gastroenterology, Hepatology and Infectious Diseases, Otto-von-Guericke University Magdeburg, Magdeburg, Germany \\ e Department of Gastroenterology, Medical Academy, Lithuanian University of Health Sciences, Kaunas, Lithuania \\ ${ }^{\mathrm{f}}$ Gastroenterology Unit, A.O. Mauriziano, Turin, Italy \\ ${ }^{g}$ Department of Surgery, Inselspital Bern, Bern, Switzerland \\ h Department of Surgery, Helsinki University Central Hospital, Helsinki, Finland \\ ${ }^{\mathrm{i}}$ Institute of Community Medicine, University Medicine Greifswald, Greifswald, Germany \\ ${ }^{\mathrm{j}}$ Department of Internal Medicine, Cardarelli Hospital, Naples, Italy \\ k Department of Gastroenterology, Oslo University Hospital, Oslo, Norway \\ ${ }^{1}$ Department of Surgery, Technical University of Munich, Munich, Germany
}

\section{A R T I C L E I N F O}

\section{Article history:}

Received 3 January 2017

Received in revised form

26 July 2017

Accepted 30 July 2017

Available online 31 July 2017

\section{Keywords:}

Chronic pancreatitis

Liver cirrhosis

Co-incidence

Lifestyle factors

Pancreatic pain

\begin{abstract}
A B S T R A C T
Background \& objectives: Chronic pancreatitis (CP) and liver cirrhosis (LC) are common gastroenterological disorders but their co-incidence is considered to be rare. This study was designed to identify lifestyle factors that are associated with the development of concomitant LC in patients with CP. Methods: In a retrospective case-control study between 2000 and 2005122 patients with both CP and LC and 223 matched control patients with CP and no known liver disease were identified in 11 European university medical centers. Another 24 patients and $48 \mathrm{CP}$ controls were identified in the period between 2006 and 2012.

Results: Alcoholism was most commonly regarded as aetiology for both CP (82.2\%; $95 \%$ confidence interval (CI): 75.0-88.0\%) and LC (79.5\%; 95\% CI: 72.0-85.7\%) as compared to controls with CP only (68.6\%; 95\% CI: $62.7-74.1 \%)$. The preferred type of alcoholic beverage and pattern of alcohol intake were the only significant lifestyle factors in multivariate analysis. Frequency of alcohol intake $(p=0.105)$ and smoking status ( $\mathrm{p}=0.099)$ were not significant in bivariate analysis and dropped out of the multivariate model. Recurrent and chronic pancreatic pain was observed more often in patients with only $\mathrm{CP}$, whereas gallstones were more common in individuals with both chronic disorders.

Conclusions: These findings indicate that certain lifestyle factors might be important for the development of concomitant CP and LC. More studies will be needed to identify additional genetic and environmental factors underlying this association.
\end{abstract}

() 2017 IAP and EPC. Published by Elsevier B.V. All rights reserved.

\section{Introduction}

Although chronic pancreatitis (CP) and liver cirrhosis (LC) are quite frequent gastroenterological disorders that share common risk factors, the co-incidence of both diseases is considered to be rare $[1,2]$. Clinical studies reported a co-incidence of cirrhosis in around $12.5-17.0 \%$ of patients with $\mathrm{CP}[3,4]$ and a co-incidence of CP of $6.6-16.0 \%$ in patients with LC $[1,3,5]$. Mostly alcoholism was

\footnotetext{
* Corresponding author. Department of Medicine A, University Medicine Greifswald, Ferdinand-Sauerbruch-Str., D-17475 Greifswald, Germany.

E-mail address: aghdassi@uni-greifswald.de (A.A. Aghdassi).
} 
an underlying etiologic factor $[1,3,4]$. Some studies with smaller patient numbers showed an even higher association of both diseases with up to $38 \%$ concomitant chronic pancreatitis in liver cirrhotics $[5,6]$. However, in a recent study in patients who underwent liver transplantation - mostly due to alcohol related liver diseases prevalence of $\mathrm{CP}$ was only detected in $3.8 \%$ of the cases [7]. Autopsy studies showed a markedly higher co-incidence of LC in individuals with $\mathrm{CP}$ and a history of alcohol abuse with a range of about 18-39\%. These numbers were even higher when all liver diseases including hepatic steatosis were included as a co-morbidity of $\mathrm{CP}$ $[8,9]$.

Most clinical studies require histology for definite diagnosis of LC. Since pancreatic histology is rarely available, findings of imaging methods including endoscopic retrograde cholangiopancreatography (ERCP) as an invasive procedure or exocrine pancreatic functions tests were often used for the diagnosis of CP. Recently the German guidelines on chronic pancreatitis evaluated the significance of different imaging tools such as transabdominal and endoscopic ultrasound (EUS), computed tomography (CT), magnetic resonance imaging (MRI), cholangiopancreatography (MRCP) and ERCP for diagnosis of CP [10]. Endoscopic retrograde pancreatography (ERP) was long considered to be the gold standard using the Cambridge Classification that meanwhile has been adopted for other non-invasive imaging methods [11]. Due to its higher risk for complications ERP is increasingly replaced by alternative non-invasive imaging procedures unless interventional procedures are necessary [10].

Expectation of a high co-incidence of $\mathrm{CP}$ and $\mathrm{LC}$ is justified, since both disorders share common risk factors and respective pathogenesis shows similarities in both organs. Both CP and LC are irreversible inflammatory disorders that are characterized by parenchymal cell degeneration, extra-cellular matrix proliferation [12] with development of fibrosis and inflammatory cell infiltration. Both disorders can also have a biliary [13] or autoimmune [14] pathogenesis. Ultimately, these changes lead to an organ insufficiency with loss of function of both, the pancreas and the liver $[15,16]$. Activated pancreatic (PSC) and hepatic stellate cells (HSC) critically contribute to organ fibrosis and both cell types share homologies that make a common origin of this cell type possible [17]. Furthermore, common genetic susceptibility factors for alcohol related liver and pancreatic disorders exist. Alcohol is mainly metabolized in a stepwise process to acetaldehyde and acetate mediated by alcohol- (ADHs) and acetaldehydedehydrogenases (ALDHs) [18,19]. Variants of the ADH1B $\left(\mathrm{ADH} 1 \mathrm{~B}^{*} 2\right.$ allele) and the ALDH2 gene $\left(\mathrm{ALDH} 2 * 1 /{ }^{*} 1\right)$ were detected in alcoholic liver cirrhosis and chronic pancreatitis [20]. Recent studies indicate that polymorphisms of ADH3 and variants of carboxyl ester lipase (CEL), a fatty acid ethyl ester (FAEE) synthetizing enzyme involved in non-oxidative ethanol metabolization, might also contribute to either alcoholic CP or LC [21,22].

However only $15 \%$ of alcoholics ultimately develop LC, $5 \%$ CP and less than $1 \%$ both diseases [23]. Noteworthy, the majority of heavy alcohol consumers (ca. 80\%) remains without any evident clinical abnormalities [6,23]. Moreover, only a few studies attempted to find risk factors that predispose to either LC or CP, but so far these results are inconclusive. Earlier and heavier alcohol consumption, early onset of nicotine abuse or a lower socio-behavioural status seem to be stronger associated with CP than LC [4,24].

For these reasons, we aimed to quantify and characterize the specific subtype of patients with concomitant CP and LC in a multicenter approach. Special attention was drawn to alcohol consumption as a known risk factor for both disorders as well as smoking status, education level and pancreatic pain in patients with both $\mathrm{CP}$ and $\mathrm{LC}$ compared to individuals with $\mathrm{CP}$ alone.

\section{Methods}

\section{Design of the study}

A retrospective multicenter study was performed at 11 European university hospitals, that consisted of 5 German (DE: Greifswald, Heidelberg, Hamburg, Mannheim, Magdeburg), two Italian (IT: Naples, Turin) and one center each from Lithuania (LT: Kaunas), Finland (FI: Helsinki), Switzerland (CH: Bern) and Norway (NO: Oslo). This study was part of the 4th class of the multinational Pancreas 2000 program organized by the Karolinska Institute and the European Pancreatic Club. The aim of this education and research program is to develop the next generation of pancreatologists to the highest standard of expertise and to build firm networks for the conduction of international projects and studies [25]. Retrieval of data was performed in the same way at all centers. For each patient with both $\mathrm{CP}$ and $\mathrm{LC}$ two patients with $\mathrm{CP}$ but no known liver disease were selected having the same gender and age (maximum \pm 2 years). Patients with a history of liver disorder in their medical history, elevated liver enzymes on routine laboratory examination or signs of liver disease on routine imaging, i.e. abdominal ultrasound, CT or MRI were not considered as control patients. Control patients were always recruited from the same university medical center. Patient files from each hospital were screened first for ICD-10 codes for CP (K86.0 alcohol-induced CP, K86.1 CP by other origin) and LC (K70.3 alcoholic LC, K71.7 toxic liver disease with fibrosis or cirrhosis and K74.3-K74.6). All diagnoses found by the ICD-10 screening were revised according to the definitions for $\mathrm{CP}$ and $\mathrm{LC}$ as described below and only patients that fulfilled the diagnostic criteria were finally selected. In case of multiple admissions archival clinical files were included in order to reduce missing information as much as possible. Patients were not contacted for collection of additional data.

Finally, 122 patients with concomitant CP and LC and 223 matched patients with $\mathrm{CP}$ only were detected within the time period of 2000-2005. An additional 24 patients with both CP and LC and their respective CP controls (48 patients) were recruited from the university hospital Greifswald in the time period from 2006 to 2012.

\section{Diagnosis of chronic pancreatitis and liver cirrhosis}

Diagnosis of CP was established using the Mayo-Clinic-Score based on histomorphological, imaging and functional changes of the pancreas [26]. Points from 1 to 4 were attributed to different morphologic and functional features and a total score of $\geq 4$ confirmed the diagnosis of CP. Presence of either calcifications in any imaging modality (transabdominal ultrasound, endoscopic ultrasound, computed tomography) or unequivocal histologic changes for chronic pancreatitis were sufficient as single parameters for diagnosis of $\mathrm{CP}$.

Liver cirrhosis was diagnosed according to the criteria published by Podolsky et al. [27]. Proven cirrhosis on histology was sufficient for diagnosis. Whenever histology was not available diagnosis was established based on signs of cirrhosis on imaging modalities and symptoms for hepatic decompensation such as ascites, hepatic encephalopathy or portal hypertension.

\section{Patient's medical history}

From each patient age, gender and ethnicity were recorded. Where appropriate age of death and, where available, age of first diagnosis of CP and LC were noted as well.

To register the history of alcohol consumption, the daily amount, frequency and duration of alcohol intake as well as the favorite type 
of alcoholic drink were documented. Pattern of alcohol intake was quantified as either "no intake", "slight ( $\leq 25$ g/day)", "moderate (25-50 g/day)" or "heavy (>50 g/day)". If available maximum amount of daily alcohol consumption was recorded. The frequency was recorded using the options "daily", "weekly" or "irregularly", preferred type of alcoholic beverage was either "beer", "wine", "hard liquor" or "other". Preferred type of alcoholic beverage was regarded as the most commonly consumed alcoholic beverages and multiple options were accepted. Alcohol consumption was calculated using standard alcohol content for each alcoholic drink (for beer $5 \%$ (alc/vol), wine $10 \%$, hard liquor $40 \%$ ).

Smoking status was assessed using the items "never smoked", "past smoker" or "current smoker". The total amount was recorded in pack years, defined as the number of cigarette packs multiplied by the number of years the patient has smoked.

Demographic questions included education (academic, nonacademic) and body mass index (body weight in $\mathrm{kg} /$ (height in $\mathrm{m})^{2}$ ). Abdominal pain in chronic pancreatitis was defined as reported by Ammann et al. in either recurrent (type A) or constant (type B) episodes of pain or no pain [28]. Lastly the presence or absence of gallstones was recorded.

\section{Statistical analysis}

Data were collected using a Microsoft Excel database. For continuous variables histograms were visually explored and descriptive statistics produced. In order not to impair the matching, missing observations were categorized as unknown and included as a separate category. Conditional logistic regression (clogit command) was used for the analysis of the matched case-control pairs. First each variable was tested for associations with the development of both LC and CP (as compared to CP only). Variables with a p-value of less than 0.2 in the bivariate analyses were included in the main effect model. Backward selection was applied until only variables with a p-value of less than 0.05 remained in the model, which were tested for two-way interactions. Results were given as odds ratio (OR) with $95 \%$ confidence interval to show the specific risk for concurrent liver cirrhosis and chronic pancreatitis. All computations were carried out using STATA 13 data analysis and statistical software (College Station, TX, USA).

\section{Results}

Overall 146 patients with concomitant CP and LC and 271 patients with only $\mathrm{CP}$ were identified in the observation period in our case-control study. In one case at the University Hospital of Turin and in three cases at the University Medicine Greifswald three control patients were matched to one patient with both diseases because the controls were identical for age and gender. In other centers (Mannheim, Magdeburg, Naples) two control patients were not always available and that is why the number of patients with $\mathrm{CP}$ is less than twice the number of patients with both CP and LC. Matching criteria were fulfilled for gender for $95 \%$ of cases and for age for $77 \%$ of cases when targeting a maximum age difference of two years (Table 1 ). Although matching criteria could not always be fulfilled, neither gender $(\mathrm{p}=0.277)$ nor age $(\mathrm{p}=0.940)$ were significantly associated with the outcome and thus not considered for further analysis. The majority of patients with concomitant $\mathrm{CP}$ and LC were male (CP\&LC: 77.4\%; CP only: 74.5\%) (Table 2). Alcohol was the most common etiological factor for $\mathrm{CP}$ (both groups) and LC (cases only), but was more commonly recorded as aetiology in case patients for both CP $(82.2 \%$; 95\% confidence interval (CI): 75.0-88.0\%) and LC (79.5\%; 95\% CI: 72.0-85.7\%) as compared to controls with CP only (68.6\%; 95\% CI: 62.7-74.1\%).

\section{Risk factors}

Primarily, the focus was set on nicotine and alcohol abuse, since alcohol is regarded to be a common risk factor CP and LC. Secondly, smoking, a frequently observed habit, can aggravate chronic disorders. Descriptive statistics for categorical and continuous variables are shown in Tables 3 and 4, respectively, and bivariate results in Table 5.

\section{Smoking status}

Median number of pack years was similar in both groups and the number of pack years showed no significant association with the outcome in the bivariate analysis $(\mathrm{p}=0.388)$. There was a trend towards a higher frequency of non-smoking history in patients with only CP compared to those with both chronic disorders ( $14.4 \% \mathrm{vs}$. $10.3 \%)$.

\section{Alcohol drinking habits}

The median amount of alcohol intake was numerically higher in $\mathrm{CP}$ and $\mathrm{LC}$ patients $(96.0 \mathrm{~g} / \mathrm{d})$ compared to controls with CP $(60.0 \mathrm{~g} /$ $\mathrm{d})$. The continuous variables daily amount $(\mathrm{p}=0.231)$ and duration of alcohol intake $(\mathrm{p}=0.222)$ were not significant. In the bivariate model, associations with concomitant LC and CP were significant for the preferred type of alcoholic beverage $(p=0.003)$ and pattern of alcohol intake $(\mathrm{p}=0.014)$ and not significant for frequency of alcohol intake $(\mathrm{p}=0.105)$ and smoking status $(\mathrm{p}=0.099)$ (Table 5). It is noteworthy, that some patients had reported more than one preferred type of alcoholic beverage, e.g. beer and spirits. These observations were categorized as 'multiple (preferred beverages)'. Therefore, the odds ratio for wine only refers to those patients who selected wine as the only preferred beverage.

\section{Body mass index and education level}

Median BMI was similar in both groups. Neither BMI $(\mathrm{p}=0.364)$ nor education ( $\mathrm{p}=0.252$ ), subdivided in academic and nonacademic education, showed a significant association with developing CP alone or in combination with LC.

\section{Identification of risk factors in a multivariate analysis}

A multivariate regression analysis was performed in order to detect independent risk factors for the co-incidence of CP and LC. Pattern of alcohol intake, preferred type of alcoholic beverage, frequency of alcohol intake and smoking status were included in the main effect model. The OR for CP and LC was 4.5 (95\%-CI 1.805-11.078) in patients with preferred wine consumption compared to patients with preferred beer consumption $(\mathrm{p}=0.001)$. For slight alcohol intake in CP\&LC patients the OR was 0.273 (95\%CI $0.111-0.674)$ compared to heavy alcohol intake $(\mathrm{p}=0.005)$ (Table 6).

Gallstones and differential presence of pancreatic pain in pancreatic and liver disorders

Presence of gallstones and pancreatic pain both showed strong associations with patients reporting LC and CP combined as compared to CP alone. In patients with both LC and CP the OR was 0.205 (95\%-CI 0.110-0.380; $\mathrm{p}<0.001$ ) for recurrent pain and 0.178 (95\%-CI 0.079-0.402; p < 0.001) for chronic pain compared to absence of pain. OR was $2.25(95 \%-C I 1.240-4.062 ; \mathrm{p}=0.008)$ in 
Table 1

Fulfilment of matching criteria per study center.

\begin{tabular}{|c|c|c|c|c|c|c|}
\hline \multirow[t]{2}{*}{ Center } & \multicolumn{2}{|c|}{ Number of } & \multirow[t]{2}{*}{ Ratio: No. of controls per case } & \multicolumn{3}{|c|}{$\%$ of controls fulfilling criteria } \\
\hline & Cases & Controls & & Gender & $\begin{array}{l}\text { Age } \\
\text { ( } \pm 2 \text { years })\end{array}$ & $\begin{array}{l}\text { Age } \\
( \pm 4 \text { years })\end{array}$ \\
\hline Greifswald, DE & 41 & 85 & 2.07 & $100 \%$ & $79 \%$ & $93 \%$ \\
\hline Hamburg, DE & 8 & 16 & 2.00 & $100 \%$ & $38 \%$ & $50 \%$ \\
\hline Heidelberg, DE & 15 & 30 & 2.00 & $73 \%$ & $47 \%$ & $70 \%$ \\
\hline Magdeburg, DE & 14 & 21 & 1.50 & $100 \%$ & $81 \%$ & $100 \%$ \\
\hline Mannheim, DE & 37 & 61 & 1.65 & $100 \%$ & $98 \%$ & $100 \%$ \\
\hline Bern, $\mathrm{CH}$ & 3 & 6 & 2.00 & $100 \%$ & $17 \%$ & $67 \%$ \\
\hline Helsinki, FI & 3 & 6 & 2.00 & $33 \%$ & $100 \%$ & $100 \%$ \\
\hline Naples, IT & 10 & 15 & 1.50 & $100 \%$ & $73 \%$ & $87 \%$ \\
\hline Turin, IT & 7 & 15 & 2.14 & $100 \%$ & $93 \%$ & $100 \%$ \\
\hline Kaunas, LT & 7 & 14 & 2.00 & $100 \%$ & $86 \%$ & $86 \%$ \\
\hline Oslo, NO & 1 & 2 & 2.00 & $50 \%$ & $0 \%$ & $0 \%$ \\
\hline Total & 146 & 271 & 1.86 & 95\% & $77 \%$ & $89 \%$ \\
\hline
\end{tabular}

Bold and italics indicates $\mathrm{P}<0.05$ is considered to be statistically significant.

Table 2

Number and gender of patients from each participating center having both chronic pancreatitis and liver cirrhosis (CP \& LC) or only chronic pancreatitis (CP).

\begin{tabular}{|c|c|c|c|c|}
\hline Participating center & Patients with $\mathrm{CP} \& \mathrm{LC}$ & No. of males & Patients with only $\mathrm{CP}$ & No. of males \\
\hline Greifswald, DE & 41 & $32(78.0 \%)$ & 85 & $67(78.8 \%)$ \\
\hline Hamburg, DE & 8 & $4(50.0 \%)$ & 16 & $8(50.0 \%)$ \\
\hline Heidelberg, DE & 15 & $13(86.7 \%)$ & 30 & $18(60.0 \%)$ \\
\hline Magdeburg, DE & 14 & $10(71.4 \%)$ & 21 & $15(71.4 \%)$ \\
\hline Mannheim, DE & 37 & $29(78.4 \%)$ & 61 & $45(73.8 \%)$ \\
\hline Bern, $\mathrm{CH}$ & 3 & $2(66.7 \%)$ & 6 & $4(66.7 \%)$ \\
\hline Helsinki, FI & 3 & $1(33.3 \%)$ & 6 & $6(100.0 \%)$ \\
\hline Naples, IT & 10 & $10(100.0 \%)$ & 15 & $15(100.0 \%)$ \\
\hline Turin, IT & 7 & $5(71.4 \%)$ & 15 & $11(73.3 \%)$ \\
\hline Kaunas, LT & 7 & $6(85.7 \%)$ & 14 & $12(85.7 \%)$ \\
\hline Oslo, NO & 1 & $1(100.0 \%)$ & 2 & $1(50.0 \%)$ \\
\hline Total & 146 & $113(77.4 \%)$ & 271 & $202(74.5 \%)$ \\
\hline
\end{tabular}

CP\&LC patients with gallstones compared to absence of gallstone disease (Table 7).

\section{Discussion}

This study evaluated lifestyle factors, in particular alcohol consumption and smoking status in a cohort of patients with concomitant chronic pancreatitis and liver cirrhosis compared to individuals with chronic pancreatitis alone. In addition the distribution of different subtypes of pancreatic pain was assessed in these patients. Multivariate conditional regression analysis identified the preferred type of alcoholic beverage (wine) and pattern of alcohol intake (slight versus heavy) as lifestyle risk factors increasing the odds of developing liver cirrhosis in addition to chronic pancreatitis.

In general the majority of patients with $\mathrm{CP}$ and $\mathrm{LC}$ or $\mathrm{CP}$ alone were male and alcoholism was found to be the most common etiologic factor for both disorders. However, there was no significant association of consumed alcohol amount per day in that group. This observation is quite surprising when assuming that development of both diseases is the consequence of a heavier alcohol abuse. There are other studies that evaluated drinking habits in patients with LC or CP and could not find differences in the amount of daily alcohol intake, respectively $[4,29]$. Patients with alcoholic CP reported their highest alcohol intake during younger years (between the age of 20 and 30 years) and the onset of alcoholism was quite often observed in adolescence [4]. However these studies concentrated on patients with either chronic pancreatitis or liver cirrhosis but did not include a group with both disorders like ours. One underlying reason is the small number of patients who are usually diagnosed with both chronic disorders together, compared to individuals suffering from only CP or LC. Due to the multicenter approach we could overcome this limiting factor and were able to characterize 146 patients with both disorders, which is, to the best of our knowledge the largest study investigating the combination of both diseases. Prevalence of chronic pancreatitis in liver cirrhotic patients is presumably higher than initially expected as a substantial number of patients with alcoholic liver disorders showed concomitant exocrine pancreatic insufficiency and had a diagnosis of chronic pancreatitis [28].

Bivariate analysis indicated that type of alcoholic beverage and the pattern of alcohol consumption correlated with the incidence of concomitant $\mathrm{CP}$ and LC. Wine drinkers suffered more often from both diseases as compared to beer drinkers whereas in patients drinking only slight amounts of alcohol (as compared to heavy intake group) odds ratio was lower for developing both CP and LC. The frequency of alcohol consumption dropped out of the multivariate model. The type of alcoholic beverage as an etiological factor for either acute or chronic pancreatitis has been investigated with conflicting results [30]. Drinking of hard liquors imposes a greater risk for both acute and chronic pancreatitis [31]. Other studies showed that drinking beer predisposes to alcoholic pancreatitis [32,33].

Wilson et al. compared drinking habits in patients with alcoholic pancreatitis and cirrhosis and found no significant differences [32]. There was a tendency that patients with alcoholic cirrhosis consumed more wine and less beer. There were no differences regarding drinking patterns (either daily or episodic consumption of higher amounts) between these two groups. In a Japanese study on male alcoholics consumption of high-alcohol drinks (spirits) with an alcohol content of at least $25 \%$ was related to alcoholic CP [34]. This observation could not be reproduced in a recent European 
Table 3

Descriptive statistics for categorical variables stratified by disease group (CP \& LC: both chronic pancreatitis and liver cirrhosis; CP: only chronic pancreatitis).

\begin{tabular}{|c|c|c|c|}
\hline Variable & Category & $\begin{array}{l}\text { Patients with CP \& LC } \\
(\mathrm{n}=146)\end{array}$ & $\begin{array}{l}\text { Patients with CP } \\
(\mathrm{n}=271)\end{array}$ \\
\hline \multirow[t]{3}{*}{ Education level } & Academic & $9(6.2 \%)$ & $22(8.1 \%)$ \\
\hline & Non-academic & $72(49.3 \%)$ & $143(52.8 \%)$ \\
\hline & Unknown & $65(44.5 \%)$ & $106(39.1 \%)$ \\
\hline \multirow[t]{5}{*}{ Pattern of alcohol intake } & None & $15(10.3 \%)$ & $26(9.6 \%)$ \\
\hline & Slight & $13(8.9 \%)$ & $40(14.8 \%)$ \\
\hline & Moderate & $21(14.4 \%)$ & $47(17.3 \%)$ \\
\hline & Heavy & $51(34.9 \%)$ & $81(29.9 \%)$ \\
\hline & Unknown & $46(31.5 \%)$ & $77(28.4 \%)$ \\
\hline \multirow[t]{7}{*}{ Preferred type of alcoholic beverage } & No alcohol consumption & $15(10.3 \%)$ & $26(9.6 \%)$ \\
\hline & Beer & $23(15.8 \%)$ & $65(24.0 \%)$ \\
\hline & Wine & $25(17.1 \%)$ & $25(9.2 \%)$ \\
\hline & Spirits & $11(7.5 \%)$ & $23(8.5 \%)$ \\
\hline & Other & $0(0.0 \%)$ & $2(0.7 \%)$ \\
\hline & Multiple selections & $20(13.7 \%)$ & $35(12.9 \%)$ \\
\hline & Unknown & $52(35.6 \%)$ & $95(35.1 \%)$ \\
\hline \multirow[t]{5}{*}{ Frequency of alcohol intake } & None & $15(10.3 \%)$ & $26(9.6 \%)$ \\
\hline & Irregularly & $7(4.8 \%)$ & $28(10.3 \%)$ \\
\hline & Weekly & $7(4.8 \%)$ & $10(3.7 \%)$ \\
\hline & Daily & $65(44.5 \%)$ & $122(45.0 \%)$ \\
\hline & Unknown & $52(35.6 \%)$ & $85(31.4 \%)$ \\
\hline \multirow[t]{4}{*}{ Smoking status } & Never & $15(10.3 \%)$ & 39 (14.4\%) \\
\hline & Past & $23(15.8 \%)$ & $42(15.5 \%)$ \\
\hline & Present & 79 (54.1\%) & $149(55.0 \%)$ \\
\hline & Unknown & 29 (19.9\%) & $41(15.1 \%)$ \\
\hline \multirow[t]{3}{*}{ Weight loss } & None & $22(15.1 \%)$ & $50(18.5 \%)$ \\
\hline & Present & $12(8.2 \%)$ & $26(9.6 \%)$ \\
\hline & Unknown & $112(76.7 \%)$ & $195(72.0 \%)$ \\
\hline \multirow[t]{3}{*}{ Gallstones } & None & 104 (71.2\%) & 223 (82.3\%) \\
\hline & Present & 37 (25.3\%) & $44(16.2 \%)$ \\
\hline & Unknown & $5(3.4 \%)$ & $4(1.5 \%)$ \\
\hline \multirow[t]{4}{*}{ Pain } & None & $45(30.8 \%)$ & $31(11.4 \%)$ \\
\hline & Recurrent & $60(41.1 \%)$ & $172(63.5 \%)$ \\
\hline & Chronic & $17(11.6 \%)$ & $47(17.3 \%)$ \\
\hline & Unknown & $24(16.4 \%)$ & $21(7.7 \%)$ \\
\hline
\end{tabular}

Table 4

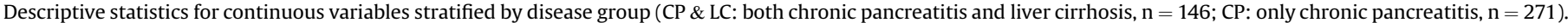

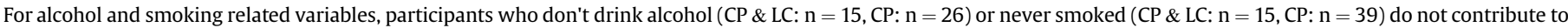
missing values. iqr $=$ interquartile range.

\begin{tabular}{|c|c|c|c|c|c|c|c|c|}
\hline \multirow[t]{2}{*}{ Variable } & \multicolumn{4}{|c|}{$\mathrm{LC} \& \mathrm{CP}$} & \multicolumn{4}{|c|}{ CP only } \\
\hline & $\mathrm{n}$ & median & iqr & range & $\mathrm{n}$ & median & iqr & range \\
\hline BMI & 118 & 23.2 & $4.8-20.2$ & $25.5-13.8$ & 210 & 23.2 & $20.7-26.7$ & $14.2-41.5$ \\
\hline Alcohol amount & 94 & 96.0 & $80.4-47.0$ & $120.0-3.0$ & 149 & 60.0 & $31.0-100.0$ & $4.0-275.0$ \\
\hline Alcohol duration & 66 & 21.7 & $11.3-10.0$ & $30.0-0.4$ & 94 & 20.0 & $10.0-30.0$ & $1.0-60.0$ \\
\hline Pack years & 91 & 34.3 & $25.3-19.0$ & $47.5-2.0$ & 151 & 30.0 & $20.0-46.0$ & $1.0-102.0$ \\
\hline
\end{tabular}

study that reported a significantly higher number of beer drinkers in alcoholic CP compared to LC. Wine drinkers were more prone to the development of liver cirrhosis, however this was not statistically significant ( $16.3 \%$ vs. $10.6 \%$, n.s.) [4].

Neither bivariate nor multivariate analysis showed a correlation of smoking status with concurrent CP and LC. So far there is a lack of studies investigating both chronic disorders together on this matter. Lowenfels et al. found that smoking was more related to alcoholic CP than to alcoholic LC in a group of male American Indians who had similar drinking habits [35]. These observations were confirmed by a French group, that reported on a higher proportion of smokers among CP patients than alcoholic liver cirrhotics. No significant differences were found regarding the amount of tobacco consumption (measured in g/day) [24].

Moreover, gallstones were often found in patients with both chronic diseases. However this finding does not imply that gallstone disease predisposes to concurrent LC and CP. The higher frequency of gallstones in liver cirrhotics might be a consequence of the liver disease. An altered composition of the bile including an increased secretion of unconjugated bilirubin with an increased hydrolysis of conjugated bilirubin, and an impaired motility of the gallbladder are discussed as potential underlying mechanisms [36].

Pancreatic pain is the hallmark and cardinal symptom of $\mathrm{CP}$, which is usually manifested as recurrent or chronic pain that both noticeably impairs quality of life [28]. In our study, the majority of patients with solely $\mathrm{CP}$ reported recurrent pain (63.5\%) that clearly exceeded other qualities of pain. Patients with both CP and LC more frequently did not have any pain at all. So far data on the frequency of pancreatic pain in subjects with concurrent chronic fibrotic disorders is missing and attempts to explain these observations are limited. One hypothesis could be that pancreatic secretion is often increased in patients with alcoholic LC that leads to a hypersecretory state and reduction of pancreatic juice stasis that finally protects from protein plug or pancreatic stone formation in the pancreatic duct $[9,37]$. On the other hand, alcohol itself reduces the function of CFTR in the pancreatic duct leading to decreased fluid 
Table 5

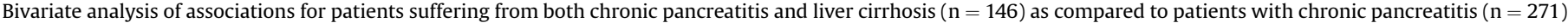
only in a matched multi-center case-control study.

\begin{tabular}{|c|c|c|c|c|}
\hline Variable & Category & Odds ratio & 95\% confidence interval & P-value \\
\hline \multirow[t]{5}{*}{ Pattern of alcohol intake } & Heavy & Ref & & \\
\hline & None & 0.782 & $0.353-1.735$ & 0.546 \\
\hline & Slight & 0.355 & $0.155-0.815$ & 0.014 \\
\hline & Moderate & 0.560 & $0.278-1.128$ & 0.105 \\
\hline & Unknown & 0.890 & $0.512-1.548$ & 0.680 \\
\hline \multirow[t]{6}{*}{ Preferred type of alcoholic beverage } & Beer & Ref & & \\
\hline & Wine & 3.541 & $1.532-8.183$ & 0.003 \\
\hline & Spirits & 1.514 & $0.602-3.807$ & 0.379 \\
\hline & Multiple & 2.074 & $0.926-4.644$ & 0.076 \\
\hline & Unknown or other & 1.415 & $0.733-2.733$ & 0.301 \\
\hline & Not applicable & 1.801 & $0.770-4.213$ & 0.175 \\
\hline \multirow[t]{5}{*}{ Frequency of alcohol intake } & Daily & Ref & & \\
\hline & None & 1.113 & $0.532-2.329$ & 0.777 \\
\hline & Irregularly & 0.486 & $0.203-1.162$ & 0.105 \\
\hline & Weekly & 1.196 & $0.427-3.349$ & 0.733 \\
\hline & Unknown & 1.103 & $0.656-1.853$ & 0.712 \\
\hline \multirow[t]{4}{*}{ Smoking status } & Never & Ref & & \\
\hline & Past & 1.377 & $0.596-3.181$ & 0.454 \\
\hline & Present & 1.404 & $0.670-2.945$ & 0.369 \\
\hline & Unknown & 2.021 & $0.875-4.667$ & 0.099 \\
\hline \multirow[t]{3}{*}{ Gallstones } & None & Ref & & \\
\hline & Present & 1.985 & $1.165-3.383$ & 0.012 \\
\hline & Unknown & 2.666 & $0.700-10.161$ & 0.151 \\
\hline \multirow[t]{4}{*}{ Pain } & None & Ref & & \\
\hline & Recurrent & 0.233 & $0.129-0.420$ & $<0.001$ \\
\hline & Chronic & 0.194 & $0.088-0.431$ & $<0.001$ \\
\hline & Unknown & 0.940 & $0.396-2.234$ & 0.889 \\
\hline
\end{tabular}

Bold and italics indicates $\mathrm{P}<0.05$ is considered to be statistically significant.

Table 6

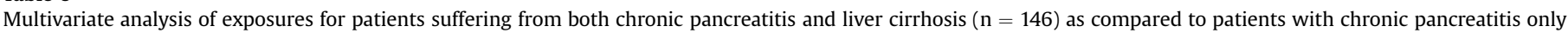
$(\mathrm{n}=271)$ in a matched multi-center case-control study.

\begin{tabular}{|c|c|c|c|c|}
\hline Variable & Category & Odds ratio & 95\% confidence interval & P-value \\
\hline \multirow[t]{5}{*}{ Pattern of alcohol intake } & Heavy & Ref & & \\
\hline & None & 1.213 & $0.459-3.202$ & 0.697 \\
\hline & Slight & 0.273 & $0.111-0.674$ & 0.005 \\
\hline & Moderate & 0.609 & $0.284-1.305$ & 0.202 \\
\hline & Unknown & 1.054 & $0.494-2.251$ & 0.891 \\
\hline \multirow[t]{5}{*}{ Preferred type of alcoholic beverage } & Beer & Ref & & \\
\hline & Wine & 4.472 & $1.805-11.078$ & 0.001 \\
\hline & Spirits & 1.305 & $0.486-3.505$ & 0.597 \\
\hline & Multiple & 1.974 & $0.843-4.621$ & 0.117 \\
\hline & Not applicable & 1.199 & $0.497-2.895$ & 0.686 \\
\hline
\end{tabular}

Bold indicates $\mathrm{P}<0.05$ is considered to be statistically significant.

Table 7

Multivariate analysis of concomitant symptoms for patients suffering from both chronic pancreatitis and liver cirrhosis $(n=146)$ as compared to patients with chronic pancreatitis only $(\mathrm{n}=271)$ in a matched multi-center case-control study.

\begin{tabular}{lllll}
\hline Variable & Category & Odds ratio & 95\% confidence interval & P-value \\
\hline Gallstones & None & Ref & & \\
& Present & 2.245 & $1.240-4.062$ & 0.008 \\
\multirow{4}{*}{ Pain } & Unknown & 3.182 & $0.700-14.467$ & 0.134 \\
& None & Ref & & \\
& Recurrent & 0.205 & $0.110-0.380$ & $<0.001$ \\
& Chronic & 0.178 & $0.079-0.402$ & $<0.001$ \\
& Unknown & 0.776 & $0.315-1.912$ & 0.581 \\
\hline
\end{tabular}

secretion [38]. Emergence of pancreatic pain might be prevented by unhindered pancreatic juice flow. The other way, a causative effect of pancreatic pain on liver cirrhosis, is rather unlikely and this relation was not intended to be established in this study. It is likely that presence of pain could be the reason for the diagnosis of $\mathrm{CP}$ in those with $\mathrm{CP}$ alone while the diagnosis of $\mathrm{CP}$ might have been made more often based on investigations rather than symptoms in those with LC and CP. Thus, the type of pain could be more of a reflection of the clinical presentation rather than propensity to develop LC. Here additional studies will be necessary for a more thorough investigation.

There are limitations of our study. Due to the retrospective design missing information is unavoidable and we had to leave out other lifestyle factors for multivariate analysis. Despite uniform data collection procedures the portions of missing data varied among the centers, in particular related to the amount of alcohol intake as well as frequency and type of alcoholic drinks. For categorical variables a separate category ("unknown") was assigned if data were missing to allow analysis of the entire data set. Further prospective studies are necessary to clarify the impact of drinking frequency, the type of alcoholic drinks or maximal daily alcohol intake. Furthermore, investigation of smoking and drinking habits as potential independent risk factors is extremely difficult since 
these two habits frequently coexist [24]. The role of gallstone disease as a risk factor for developing cirrhosis in addition to pancreatitis or a result of a liver disorder also requires more detailed analysis before it can be interpreted.

In conclusion, the co-incidence of $\mathrm{CP}$ and $\mathrm{LC}$ was not dependent on daily alcohol intake and smoking in our study. However, the preferred type of alcoholic beverage and frequency of alcohol intake might be related to concomitant $\mathrm{CP}$ and $\mathrm{LC}$ or $\mathrm{CP}$ alone, but further investigations will be necessary in order to confirm these observations. In our retrospective study we didn't analyze the impact of each alcoholic drink in cases when patients drank different types simultaneously. It seems to be very likely that environmental factors alone will not determine whether or not some chronic pancreatitis patients ultimately also develop LC. Future research will have to focus on underlying genetic factors and the biochemical effects of stellate cells that play a role for the pathogenesis of both diseases.

\section{Acknowledgements}

This work was performed and written as part of the 4th class of the Pancreas 2000 program funded and organized by the European Pancreatic Club and the Karolinska Institute, Stockholm, Sweden. The authors declare no conflicts of interest.

\section{Authors contribution}

A.A.A., M.K., I.K., P.S., J.L., E.T., G.U., T.H. and G.O.C. contributed with concept and design of the study; A.A.A., A.S., M.K., K.S., I.K., P.S., J.L., E.T., B.S., G.U., T.H. and G.O.C. contributed to acquisition and analysis of data; A.A.A. and G.O.C. wrote the manuscript; all authors made critical revisions and final approval of the manuscript.

\section{List of abbreviations}

$\begin{array}{ll}\text { Alc/vol } & \text { alcohol by volume } \\ \text { BMI } & \text { body mass index } \\ \text { CP } & \text { chronic pancreatitis } \\ \text { ERCP } & \text { endoscopic retrograde cholangiopancreatography } \\ \text { ERP } & \text { endoscopic retrograde pancreatography } \\ \text { EUS } & \text { endoscopic ultrasound } \\ \text { HSC } & \text { hepatic stellate cell } \\ \text { LC } & \text { liver cirrhosis } \\ \text { MRCP } & \text { magnetic resonance cholangiopancreatography } \\ \text { OR } & \text { odds ratio } \\ \text { PSC } & \text { pancreatic stellate cell } \\ \text { SD } & \text { standard deviation }\end{array}$

\section{References}

[1] Caradonna P, Costamagna G, Benedetti G, Gentiloni N, Gasbarrini GB. Chronic pancreatitis prevalence in liver cirrhosis. Morphological and functional study. Ital J Gastroenterol 1996;28:91-4.

[2] Cote GA, Yadav D, Slivka A, Hawes RH, Anderson MA, Burton FR, et al. Alcohol and smoking as risk factors in an epidemiology study of patients with chronic pancreatitis. Clin Gastroenterol Hepatol Official Clin Pract J Am Gastroenterol Assoc 2011;9:266-73. quiz e227.

[3] Angelini G, Merigo F, Degani G, Camplani N, Bovo P, Fratta Pasini A, et al. Association of chronic alcoholic liver and pancreatic disease: a prospective study. Am J Gastroenterol 1985;80:998-1003.

[4] Spicak J, Pulkertova A, Kralova-Lesna I, Suchanek P, Vitaskova M, Adamkova V. Alcoholic chronic pancreatitis and liver cirrhosis: coincidence and differences in lifestyle. Pancreatol Official J Int Assoc Pancreatol 2012;12:311-6.

[5] Gullo L, Casadei R, Campione O, Grigioni W, Marrano D. Alcoholic liver disease in alcoholic chronic pancreatitis: a prospective study. Ital J Gastroenterol 1995;27:69-72.

[6] Kochhar R, Sethy PK, Sood A, Nagi B, Singh K. Concurrent pancreatic ductal changes in alcoholic liver disease. J Gastroenterol Hepatol 2003;18:1067-70.

[7] Darstein F, Konig C, Hoppe-Lotichius M, Grimm D, Knapstein J, Mittler J, et al.
Impact of pancreatic comorbidities in patients with end-stage liver disease on outcome after liver transplantation. Eur J Intern Med 2014:25:281-5.

[8] Pace A, de Weerth A, Berna M, Hillbricht K, Tsokos M, Blaker M, et al. Pancreas and liver injury are associated in individuals with increased alcohol consumption. Clin Gastroenterol Hepatol Official Clin Pract J Am Gastroenterol Assoc 2009;7:1241-6.

[9] Renner IG, Savage 3rd WT, Stace NH, Pantoja JL, Schultheis WM, Peters RL. Pancreatitis associated with alcoholic liver disease. A review of 1022 autopsy cases. Dig Dis Sci 1984;29:593-9.

[10] Hoffmeister A, Mayerle J, Beglinger C, Buchler MW, Bufler P, Dathe K, et al. English language version of the s3-consensus guidelines on chronic pancreatitis: definition, aetiology, diagnostic examinations, medical, endoscopic and surgical management of chronic pancreatitis. Z Gastroenterol 2015;53: 1447-95.

[11] Sarner M, Cotton PB. Classification of pancreatitis. Gut 1984;25:756-9.

[12] Gress TM, Muller-Pillasch F, Lerch MM, Friess H, Buchler M, Beger HG, et al. Balance of expression of genes coding for extracellular matrix proteins and extracellular matrix degrading proteases in chronic pancreatitis. Z Gastroenterol 1994;32:221-5.

[13] Hernandez CA, Lerch MM. Sphincter stenosis and gallstone migration through the biliary tract. Lancet 1993;341:1371-3.

[14] Pickartz T, Mayerle J, Lerch MM. Autoimmune pancreatitis. Nat Clin Pract Gastroenterol Hepatol 2007;4:314-23.

[15] Dominguez Munoz JE. Physiopathology, diagnosis, and treatment of exocrine pancreatic insufficiency in patients with chronic pancreatitis. Gastroenterol Hepatol 2005;28(Suppl 1):22-8.

[16] Lerch MM, Mayerle J, Aghdassi AA, Budde C, Nitsche C, Sauter G, et al. Advances in the etiology of chronic pancreatitis. Dig Dis 2010;28:324-9.

[17] Erkan M, Weis N, Pan Z, Schwager C, Samkharadze T, Jiang X, et al. Organinflammation- and cancer specific transcriptional fingerprints of pancreatic and hepatic stellate cells. Mol Cancer 2010;9:88.

[18] Zintzaras E, Stefanidis I, Santos M, Vidal F. Do alcohol-metabolizing enzyme gene polymorphisms increase the risk of alcoholism and alcoholic liver disease? Hepatology 2006;43:352-61.

[19] Aghdassi AA, Weiss FU, Mayerle J, Lerch MM, Simon P. Genetic susceptibility factors for alcohol-induced chronic pancreatitis. Pancreatol Official J Int Assoc Pancreatol 2015;15:S23-31.

[20] Yokoyama A, Mizukami T, Matsui T, Yokoyama T, Kimura M, Matsushita S, et al. Genetic polymorphisms of alcohol dehydrogenase-1b and aldehyde dehydrogenase-2 and liver cirrhosis, chronic calcific pancreatitis, diabetes mellitus, and hypertension among Japanese alcoholic men. Alcohol Clin Exp Res 2013;37:1391-401.

[21] Zhong Y, Cao J, Zou R, Peng M. Genetic polymorphisms in alcohol dehydrogenase, aldehyde dehydrogenase and alcoholic chronic pancreatitis susceptibility: a meta-analysis. Gastroenterol Hepatol 2015;38:417-25.

[22] Fjeld K, Beer S, Johnstone M, Zimmer C, Mossner J, Ruffert C, et al. Length of variable numbers of tandem repeats in the carboxyl ester lipase (cel) gene may confer susceptibility to alcoholic liver cirrhosis but not alcoholic chronic pancreatitis. PLoS One 2016;11:e0165567.

[23] Dreiling DA, Koller M. The natural history of alcoholic pancreatitis: update 1985. Mt Sinai J Med N. Y 1985;52:340-2.

[24] Bourliere M, Barthet M, Berthezene P, Durbec JP, Sarles H. Is tobacco a risk factor for chronic pancreatitis and alcoholic cirrhosis? Gut 1991;32:1392-5.

[25] Gasslander T, Holmberg B, Permert J. Pancreas 2000-a new concept for education and development in pancreatology. Pancreatol Official J Int Assoc Pancreatol 2005;5:545-6.

[26] Lankisch PG, Layer P. Chronische pankreatitis. Update Diagn Ther 2000 2000;97(33):A 2169-2177.

[27] Podolsky DK, Isselbacher KJ. Cirrhosis and alcoholic liver disease. In: FASea, editor. Harrison's principles of internal medicine, vol. 14th ed.. New York: McGraw-Hill; 1998. p. 1704-10.

[28] Ammann RW, Muellhaupt B. The natural history of pain in alcoholic chronic pancreatitis. Gastroenterology 1999;116:1132-40.

[29] Nakamura Y, Kobayashi Y, Ishikawa A, Maruyama K, Higuchi S. Severe chronic pancreatitis and severe liver cirrhosis have different frequencies and are independent risk factors in male Japanese alcoholics. J Gastroenterol 2004;39: 879-87.

[30] Gerloff A, Feick P, Singer MV. Pancreas - non-alcoholic constituents and their effects. Dig Dis 2010;28:812-9.

[31] Schmidt DN. Apparent risk factors for chronic and acute pancreatitis in stockholm county. Spirits but not wine and beer. Int J Pancreatol Official J Int Assoc Pancreatol 1991;8:45-50.

[32] Wilson JS, Bernstein L, McDonald C, Tait A, McNeil D, Pirola RC. Diet and drinking habits in relation to the development of alcoholic pancreatitis. Gut 1985;26:882-7.

[33] Kristiansen L, Gronbaek M, Becker U, Tolstrup JS. Risk of pancreatitis according to alcohol drinking habits: a population-based cohort study. Am J Epidemiol 2008;168:932-7.

[34] Cichoz-Lach H, Partycka J, Nesina I, Celinski K, Slomka M, Wojcierowski J. Alcohol dehydrogenase and aldehyde dehydrogenase gene polymorphism in alcohol liver cirrhosis and alcohol chronic pancreatitis among Polish individuals. Scand J Gastroenterol 2007;42:493-8.

[35] Lowenfels AB, Zwemer FL, Jhangiani S, Pitchumoni CS. Pancreatitis in a native american indian population. Pancreas 1987;2:694-7.

[36] Acalovschi M. Gallstones in patients with liver cirrhosis: incidence, etiology 
clinical and therapeutical aspects. World J Gastroenterol WJG 2014;20 7277-85.

[37] Aparisi L, Sabater L, Del-Olmo J, Sastre J, Serra MA, Campello R, et al. Does an association exist between chronic pancreatitis and liver cirrhosis in alcoholic subjects? World J Gastroenterol WJG 2008;14:6171-9.
[38] Maleth J, Balazs A, Pallagi P, Balla Z, Kui B, Katona M, et al. Alcohol disrupts levels and function of the cystic fibrosis transmembrane conductance regulator to promote development of pancreatitis. Gastroenterology 2015;148: 427-39. e416. 